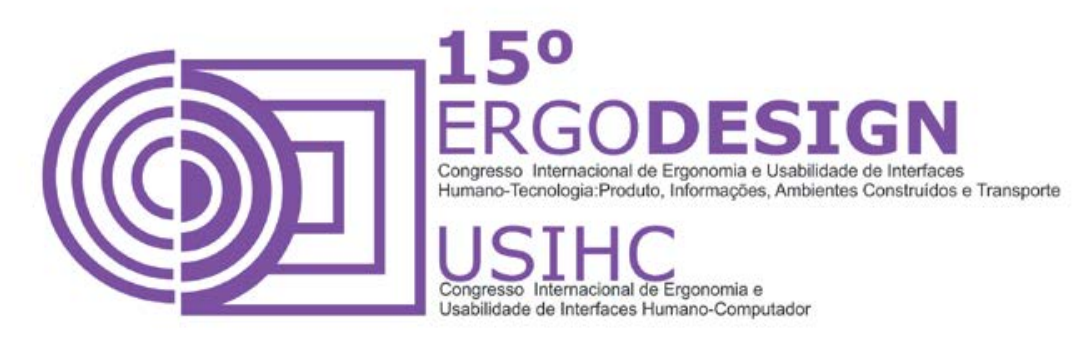

\title{
MÉTODOS PARA ANÁLISE DA EXPERIÊNCIA DO USUÁRIO EM LABORATÓRIO
}

\section{ANALYSIS METHODS FOR THE USER EXPERIENCE IN LAB}

\author{
FRANZ, Amanda Magalhães Schneider (1); \\ SANTOS, Prof. Dr. Flávio Anthero Nunes Vianna dos (2) \\ (1) Universidade do Estado de Santa Catarina - UDESC, Mestranda \\ e-mail:amandamschneider@yahoo.com.br \\ (2) Universidade do Estado de Santa Catarina - UDESC, Doutor \\ e-mail: flavioanvs@hotmail.com
}

\begin{abstract}
RESUMO
Assim como existem técnicas que auxiliam na condução de testes de usabilidade com o intuito de avaliar a eficiência e eficácia de um produto, também existem métodos específicos voltados para análise da experiência do usuário. Este tipo de estudo visa observar além dos atributos de uso, aspectos cognitivos, socioculturais e afetivos. Para isso, serão apresentados alguns métodos, específicos para análise da experiência do usuário. Estes testes podem ser realizados em laboratórios ou em campo, sendo determinante para sua escolha o tipo de atividade e tempo de duração de cada avaliação, assim como a necessidade da equipe que observará os testes.
\end{abstract}

Palavras-chave: Experiência Do Usuário, Métodos, Laboratório.

\begin{abstract}
Just as there are techniques that assist in conducting usability tests in order to evaluate the efficiency and effectiveness of a product, there are also specific methods focused on analysis of the user experience. The objective of this kind of study is observe the attributes of use, cognitive, socio-cultural and affective. For this, we introduce some specific methods to user experience analysis. These tests could be conducted in laboratory or in field, being a determining factor of your choice the kind of activity and the duration of each test, as well as the need for testing of the observation team.
\end{abstract}

Keywords: User Experience Methods, Lab. 


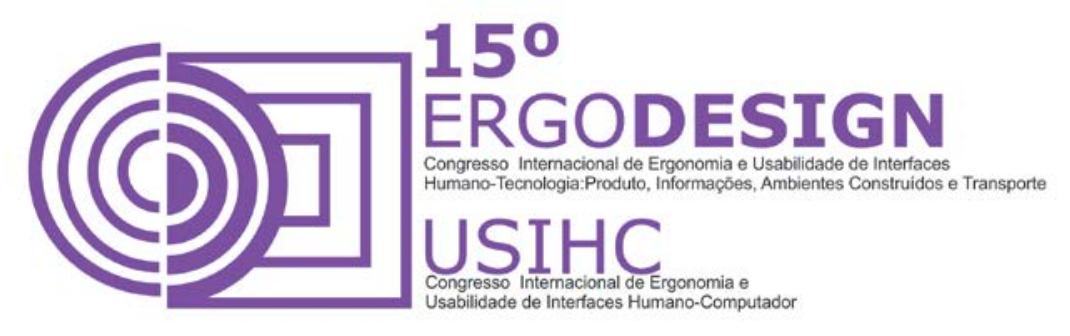

\section{INTRODUÇÃO}

Durante o processo de desenvolvimento de novos produtos ou sistemas são utilizadas técnicas e metodologias de pesquisa com o intuito de levantar informações ou validar o projeto em desenvolvimento. Estas pesquisas podem ocorrer, por exemplo, em campo, ou seja, no ambiente real do usuário, ou em um laboratório com ambiente controlado.

Antes de abordar estas técnicas é importante compreender o conceito de usabilidade e experiência do usuário. De acordo com Nielsen (1993) a usabilidade permite compreender se o sistema é bom o suficiente para satisfazer todas as necessidades e exigências dos usuários e outras partes interessadas. Neste contexto, a satisfação está relacionada à eficiência e eficácia da tarefa. Já a experiência do usuário, conforme defende Nielsen (2008), também conhecida como UX, não só inclui a usabilidade, mas também aspectos cognitivos, socioculturais e afetivos - aspectos positivos da experiência dos usuários em sua interação com os produtos além da experiência estética ou desejo de reutiliza-lo. Araujo (2014), conclui que os objetivos estão associados a usabilidade enquanto o prazer ao realizar os objetivos está relacionado com a experiência do usuário. Observa-se que os dois conceitos são complementares, no entanto, a experiência do usuário apresenta-se de maneira mais ampla, pois além dos quesitos analisados sobre a ótica da usabilidade, aborda ainda percepções estéticas e emocionais.

Teste de usabilidade é um termo usado frequentemente para se referir a qualquer técnica usada para avaliar um produto ou sistema. No entanto, de acordo com Rubin (2008) aplica-se o termo teste de usabilidade para se referir a um processo que emprega pessoas como participantes de testes que representam o público-alvo para avaliar o grau em que um produto atende a usabilidade. Para outras técnicas de avaliações que não exijam o envolvimento de usuários como parte do processo, como ocorre, por exemplo, em avaliações com peritos, não se denomina teste de usabilidade. Cada abordagem do teste tem diferentes objetivos, bem como tempo distinto e requisitos de recursos.

Identifica-se na estrutura destes laboratórios que existe um desenvolvimento natural pela utilização de ambientes que avaliem a experiência do usuário e não apenas a usabilidade. Os laboratórios dos pequenos escritórios ainda possuem a configuração clássica, apresentadas em livros de usabilidade, formada apenas por duas salas, uma de observação e outra de experimento, divididas por um falso espelho. Porém empresas maiores buscam criar ambientes próximos ao ambiente real do usuário, com a finalidade de analisar além dos aspectos relacionados ao uso e a satisfação, a experiência deste usuário.

Realizando um breve levantamento sobre as grandes empresas que utilizam estas técnicas de pesquisa, observou-se que muitas delas além de realizarem pesquisas em campo, possuem um laboratório próprio para realização de testes em ambientes controlados. Entre elas, pode-se citar: Whirlpool, Electrolux e Embraer. O Instituto Nokia de Tecnologia, também possui um laboratório de usabilidade. Além disso, percebe-se um número crescente de empresas com foco na usabilidade, que também possuem laboratórios para realização de testes, principalmente nas regiões onde se localiza um grande número de empresas de tecnologia.

Atualmente os laboratórios para realização de avaliações com usuários são configurados, 


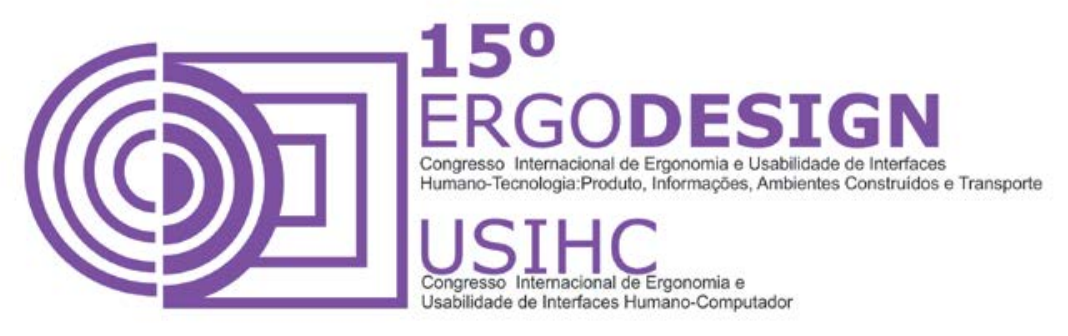

quase que exclusivamente, para realização de testes de usabilidade. No entanto, percebe-se que para desenvolver produtos que atendam às necessidades dos usuários, além de realizar avaliações para medir a eficácia e eficiência de um produto torna-se necessário avaliar a experiência que este produto desperta no usuário.

Muitas vezes o produto analisado cumpriu seu desempenho, porém não despertou nenhum sentimento positivo no usuário que despertasse o desejo de reutilizá-lo por exemplo. Para isso, faz-se necessário estudar os métodos utilizados para análise da experiência do usuário, e quais destes métodos podem ser avaliados em laboratório, uma vez que os testes em laboratórios são mais práticos para uma equipe de desenvolvimento de produto.

Portanto, os objetivos deste trabalho consistem no levantamento de métodos para avaliação da experiência do usuário, e a análise de quais podem ser aplicados em estudos em ambiente controlado. Pretende-se também utilizar os resultados deste artigo como referência para realizar o estudo de definição dos parâmetros para a construção de um ambiente controlado.

\section{UTILIZAÇÃO DE LABORATÓRIO PARA REALIZAÇÃO DE PESQUISAS PARA ANÁLISE DA EXPERIÊNCIA DO USUÁRIO}

Os testes para análise da usabilidade e experiência podem ocorrer em dois tipos de ambiente: laboratório ou em campo. Trata-se de situações distintas que têm impacto direto sobre as condições dos testes e seus resultados. De acordo com Cybis (2007) a avaliação feita em laboratório equipado com dispositivos e aparelhos de registro confere maior poder de controle e de observação da interação do usuário com o produto. O responsável pela avaliação pode modificar a sequencia ou introduzir novas tarefas, além de definir a melhor posição para as observações. Outrossim, como as avaliações são realizadas sempre no mesmo ambiente, com as mesmas variáveis, e sem a interferência de terceiros a comparação entre os resultados torna-se mais eficiente. Para PREECE (2005) nos testes realizados em laboratório o foco está nos detalhes do que os usuários fazem, ao passo que na observação de campo o contexto é importante e a ênfase está em como as pessoas interagem umas com as outras, com a tecnologia e com o ambiente.

O laboratório é um ambiente mais confortável para o avaliador, é um local seguro, silencioso e com o qual o avaliador já está acostumado, e como o deslocamento será do usuário, testes em laboratórios tornam-se mais rápidos se comparados aos testes de campo. Por outro lado, testes em laboratório não conseguem analisar como o usuário interage com o produto em um cenário real, considerando a interferência de outras pessoas e outros equipamentos. Por ser um ambiente controlado o entrevistado pode ficar desconfortável durante o teste, principalmente se na sala houver muitas pessoas ou equipamento de vídeo. Cybis (2007) entende que avaliações em laboratório são mais adequadas quando o produto ou software ainda está em desenvolvimento ou, como defende Rubin (2008), quando torna-se inviável levar o produto a campo, ou seja, quando o produto não é portátil ou é de difícil deslocamento. É indicado também quando é necessário utilizar um equipamento específico para coleta de dados que funciona melhor em um laboratório, como por exemplo, um eye-tracking. 


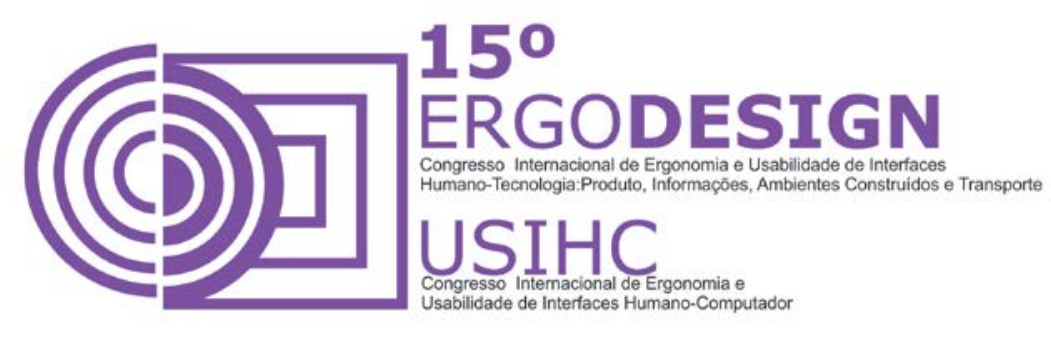

Já os testes realizados em campo permitem colocar o usuário em situações mais próximas ao contexto real de uso do produto ou software, conforme coloca CYBIS (2007). Apresenta-se como uma proposta mais confortável ao entrevistado, pois ele está em um ambiente conhecido, provavelmente em sua casa ou ambiente de trabalho, e não precisa deslocar-se até um laboratório. No entanto, como trata-se de um ambiente suscetível a constantes mudanças e interferências torna-se mais difícil controlar o teste. Sob a perspectiva do avaliador, para a realização dos testes, o campo torna-se um ambiente mais desconfortável em relação ao laboratório. A qualquer momento uma pessoa pode se aproximar do avaliador ou do usuário e interromper a avaliação. O tempo de preparação e montagem também é maior para testes realizados fora do laboratório, sendo importante considerar que muitas vezes as empresas estão testando novos conceitos, ainda em fase de desenvolvimento do produto, e nessas situações a confidencialidade dos protótipos e produtos é imperativa, o que os leva a realizar testes em laboratório.

$\mathrm{Na}$ tabela 1, pode-se observar de maneira resumida as vantagens e desvantagem em realizar testes em laboratório ou em campo

Tabela 1: vantagens e desvantagens de testes realizados em laboratório e em campo.

Fonte: a autora

\begin{tabular}{|c|c|c|c|}
\hline \multicolumn{2}{|r|}{ Laboratório } & \multicolumn{2}{|r|}{ Campo } \\
\hline 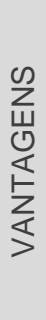 & $\begin{array}{l}\text { + confortável para o avaliador } \\
\text { + local seguro e silencioso com o qual o } \\
\text { moderador já está acostumado } \\
\text { + mais rápidos, evitando deslocamento da } \\
\text { equipe } \\
\text { + quando torna-se inviável levar o produto a } \\
\text { campo } \\
\text { + maior confidencialidade }\end{array}$ & 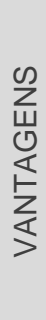 & $\begin{array}{l}\text { + situações reais de uso } \\
\text { + confortável para os entrevistados } \\
\text { + menor investimento, pois não necessita de } \\
\text { estrutura física }\end{array}$ \\
\hline 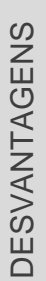 & $\begin{array}{l}\text { - não avalia situações reais de uso } \\
\text { - inibir os usuários }\end{array}$ & 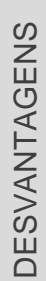 & $\begin{array}{l}\text { - torna-se difícil controlar o teste } \\
\text { - planejamento e logística tendem a ser mais } \\
\text { complexos } \\
\text { - as sessões tendem a ser mais longas } \\
\text { - oferece um espaço limitado aos } \\
\text { observadores }\end{array}$ \\
\hline
\end{tabular}

Considerando a realidade de muitas empresas, como o tempo e confidencialidade, e um controle maior do ambiente e dos dados, neste estudo optou-se pela avaliação da experiência do usuário em laboratórios. 


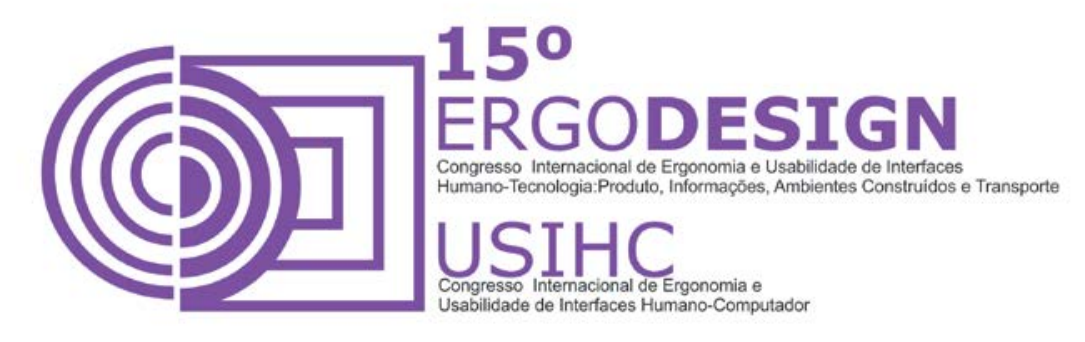

\section{MÉTODOS REFERENTES A ANÁLISE DA EXPERIÊNCIA DO USUÁRIO}

Existem métodos distintos para a avaliação de usabilidade e para avaliação da experiência do usuário. Estes métodos podem ser considerados complementares, partindo do principio de que a usabilidade está inclusa na experiência do usuário conforme defende ARAUJO (2014). Dependendo dos fatores e métricas selecionadas, os métodos de avaliação da usabilidade podem também ser utilizados para avaliar os fatores da experiência do usuário. Para tanto é necessário a identificação da fase do processo de desenvolvimento do produto em que cada método é mais bem aplicado, a fim de garantir uma experiência de uso efetiva.

Independentemente do método, o objetivo das avaliações da experiência do usuário é essencialmente o mesmo: coletar dados e produzir descrições de problemas de utilização para análise, que podem ser utilizados no processo iterativo de desenvolvimento para alcançar um nível aceitável de UX. (HARTSON et al., 2001 apud ARAUJO, 2014).

Como o presente estudo busca analisar quais métodos para análise da experiência podem ser utilizados em laboratório de avaliação, serão listados apenas os métodos referentes a experiência do usuário. De acordo com Araujo (2014) existem sete métodos para avaliação da experiência do usuário: PrEMo, Expressões faciais, ESM e DRM, CORPUS, iScale, UX Curve e cenário. Estes métodos estão apresentados na tabela 2.

Tabela 2: métodos para análise da experiência do usuário Fonte: Araujo (2014) 


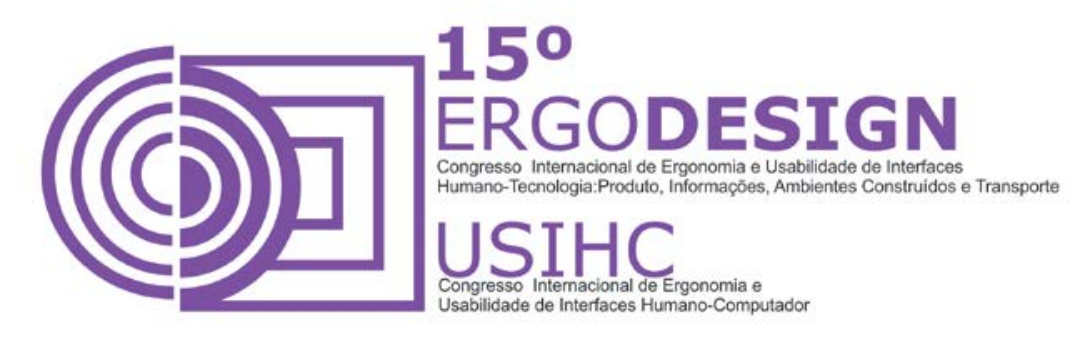

\begin{tabular}{|c|c|c|c|}
\hline NOME & \multicolumn{2}{|l|}{ AUTORES } & DESRIÇÃO \\
\hline $\begin{array}{l}\text { PREMO - PRODUCT } \\
\text { EMOTION MEASURE }\end{array}$ & \multicolumn{2}{|l|}{ DESMET, 2002} & $\begin{array}{l}\text { Utilizado para medir o sentimento despertado, } \\
\text { pelo produto, no usuário. }\end{array}$ \\
\hline $\begin{array}{l}\text { AVALIAÇÃO } \\
\text { EMOCIONAL POR } \\
\text { EXPRESSÕES FACIAIS }\end{array}$ & $\begin{array}{l}\text { DESMET ET } \\
2008\end{array}$ & AL., & $\begin{array}{l}\text { Utilizado para analisar a emoção que o produto } \\
\text { despertou no usuário, através da análise da } \\
\text { expressão facial. }\end{array}$ \\
\hline $\begin{array}{l}\text { DRM - MÉTODO DA } \\
\text { RECONSTRUÇÃO DO } \\
\text { DIA }\end{array}$ & \multicolumn{2}{|c|}{$\begin{array}{l}\text { KAHNEMAN ET AL., } \\
2004\end{array}$} & $\begin{array}{l}\text { Estabelece um processo cronológico na } \\
\text { reconstrução de experiências diárias, que permite } \\
\text { reconstruir comportamentos e emoções das } \\
\text { atividades diárias dos entrevistados. }\end{array}$ \\
\hline CORPUS & \multicolumn{2}{|c|}{$\begin{array}{l}\text { VON WILAMOWITZ- } \\
\text { MOELLENDORFF } \\
\text { ET AL., } 2006\end{array}$} & $\begin{array}{l}\text { Serve para reconstruir as mudanças na } \\
\text { experiência do usuário ao longo de um período de } \\
\text { mais de um ano. }\end{array}$ \\
\hline ISCALE & $\begin{array}{l}\text { KARAPANOS } \\
\text { AL., } 2009\end{array}$ & ET & $\begin{array}{l}\text { Auxilia os usuários de forma retrospectiva, } \\
\text { relembrando sua experiência ao longo do tempo. }\end{array}$ \\
\hline UX CURVE & $\begin{array}{l}\text { KUJALA ET } \\
2011\end{array}$ & AL., & $\begin{array}{l}\text { Investiga a atração, facilidade de uso, e o grau de } \\
\text { utilização a fim de identificar os usuários } \\
\text { satisfeitos (e o motivo da satisfação) e os } \\
\text { insatisfeitos (e o motivo da insatisfação). }\end{array}$ \\
\hline CENÁRIO & $\begin{array}{l}\text { DESMET ET } \\
2008\end{array}$ & AL., & $\begin{array}{l}\text { Conjunto de técnicas em que se descreve o uso } \\
\text { do produto ainda em sua fase inicial de } \\
\text { desenvolvimento. Tratam-se de descrições } \\
\text { narrativas feitas pelos usuários, imaginando como } \\
\text { será a utilização do produto apresentando. }\end{array}$ \\
\hline
\end{tabular}

\section{MÉTODOS UTILIZADOS EM LABORATÓRIO, PARA AVALIAR A EXPERIÊNCIA DO USUÁRIO}

Verifica-se que existem diferenças entre ambientes desenvolvidos somente para análise de usabilidade e para observação da experiência do usuário. Por isso a construção destes ambientes deve levar em consideração o tipo de estudo que se deseja realizar e os tipos de informações que serão observadas e coletadas.

Para a realização de testes de usabilidade, existem indicações para a configuração do ambiente clássico. Trata-se de um espaço para a realização do experimento (tarefas) e um local para os observadores, estes podem estar na mesma sala, ou em locais distintos, separados por um falso espelho. Esta última configuração permite que os observadores visualizem a realização dos testes, deixando o entrevistado em um espaço mais reservado, sem tanta 


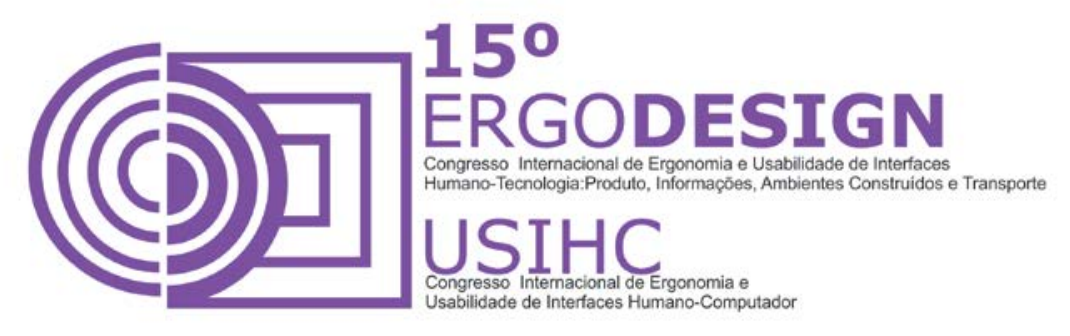

interferência, minimizando a sensação de estar sendo observado, por parte do usuário entrevistado. No entanto, caso não se tenha acesso a um laboratório como este, pode-se contar com o auxílio de câmeras que filmam o usuário durante o teste e em tempo real apresentam as imagens e áudio à equipe de projeto que está em outra sala.

Contudo é preciso saber qual percepção e quais métricas deseja-se extrair em uma determinada pesquisa e como um ambiente pode influenciar no resultado dessa coleta de dados. Em um ambiente para análise da experiência do usuário, além da realização de tarefas relacionadas ao uso do produto, também faz-se necessário a observação de aspectos relacionados a preferência estética, valor, desejo entre outros.

Como existem métodos distintos para avaliação de usabilidade e experiência do usuário, faz-se necessário avaliar se os ambientes utilizados hoje para a realização dos testes de usabilidade, são adequados para a realização de testes para o estudo da experiência do usuário. Assim, mostra-se pertinente a elaboração de métricas para a construção de ambientes controlados para a realização de testes com foco na experiência do usuário.

Levando em consideração os ambientes clássicos utilizados para realização de teste de usabilidade e analisando os métodos descritos anteriormente, para avaliação da experiência do usuário é possível elencar quais destes podem ou não ser aplicados em laboratórios.

Por se tratar de uma dinâmica, o método PrEMo pode ser aplicado em laboratório. Para isso, é necessário um ambiente reservado, com acesso a computadores, impressoras e revistas, para a coleta das imagens dos personagens, assim como papéis para a confecção dos cartões finais com as imagens e descrições. Neste caso, pode-se utilizar uma sala simples, o ambiente não precisa simular o ambiente real de uso do produto.

A Avaliação Emocional por Expressões Faciais também pode ser utilizada em laboratório. Esta é uma técnica de análise para ser aplicada em conjunto com outra técnica de pesquisa. Pode, por exemplo, ser aplicada junto a um teste de usabilidade. Neste caso, além de analisar questões relacionadas a eficiência e eficácia, a partir da análise das expressões faciais é possível observar a experiência do usuário avaliado. Ao utilizar esta técnica é importante utilizar filmagens do usuário, no momento do teste os observadores podem não perceber todas as expressões faciais realizadas pelo entrevistado. Revendo os vídeos será mais fácil perceber todas as reações do usuário.

A técnica Cenário igualmente pode ser realizada em laboratório, onde o usuário é apresentado a uma imagem ou protótipo do produto e relata ao avaliador como imagina que será o funcionamento deste equipamento.

As técnicas que são avaliadas em longo prazo, com relatos constantes sobre a experiência, não são possíveis de serem estudadas em laboratório, é essencial que elas ocorram no ambiente real do usuário. É o caso dos métodos ESM e DRM, CORPUS, iScale e UX Curve. Na imagem 1, pode-se observar a divisão dos métodos avaliados em laboratório e em campo. 

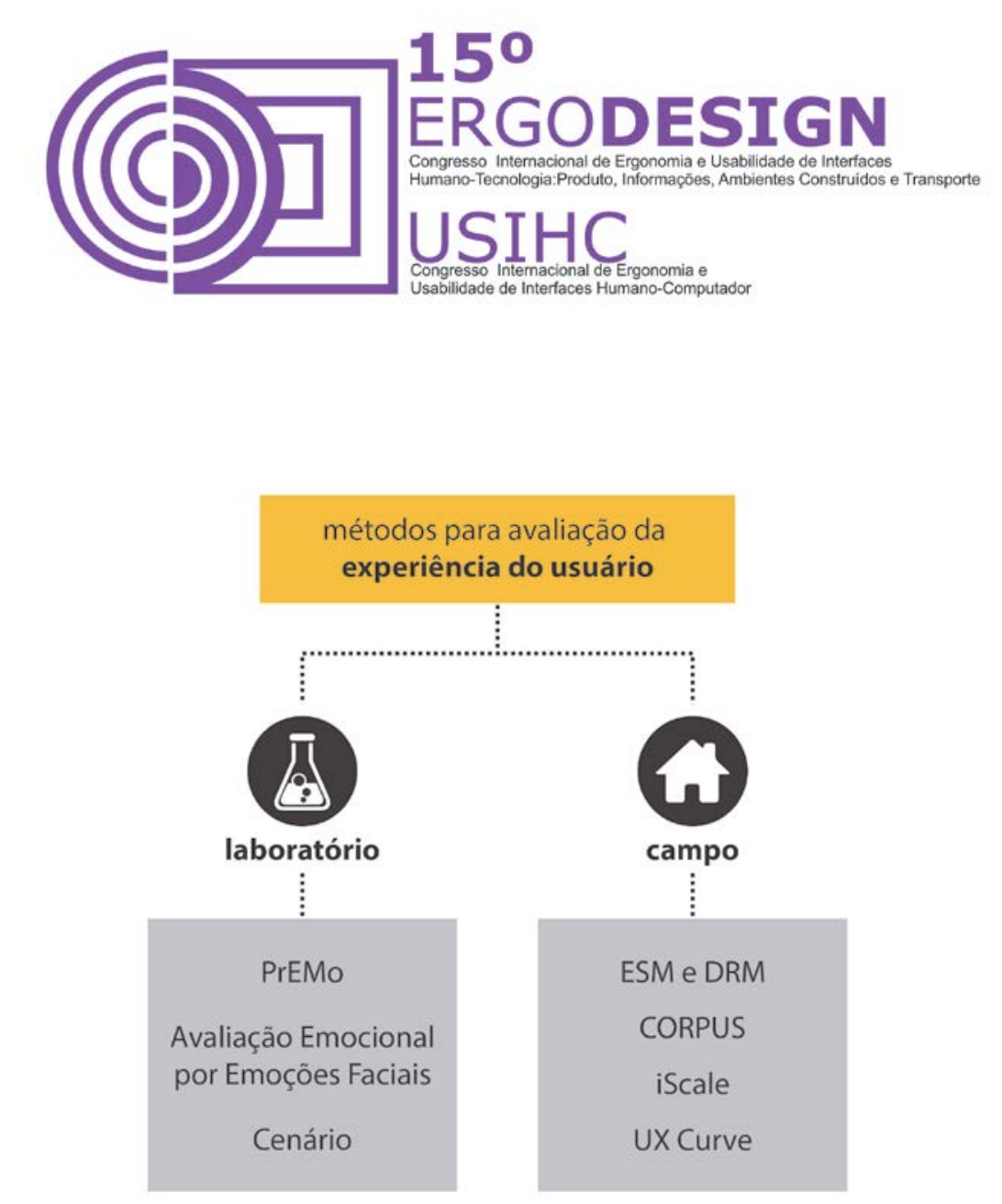

Imagem 1:

métodos para avaliação da experiência do usuário

agrupamento de

Fonte: a autora

\section{CONCLUSÃO}

A partir dos métodos para análise da experiência do usuário, definidas por Araujo (2014), observa-se que nem todos podem ser aplicados em laboratório, principalmente os métodos que necessitam de uma observação por um longo período por parte do usuário. No entanto, os métodos que visam analisar a experiência de maneira pontual são facilmente adaptados ao ambiente do laboratório. Constatou-se que as técnicas avaliadas em longo prazo, com relatos constantes sobre a experiência, demonstram ser realizadas essencialmente no ambiente real do usuário. Todavia os métodos que envolvem atividades de observação da percepção ou discussão com o usuário, realizadas em um curto espaço de tempo, podem ser executadas em laboratórios.

A observação realizada em laboratório retira o usuário de seu ambiente natural, no entanto oferece agilidade nos estudos e torna-se mais confortável à equipe observadora, uma vez que podem realizar os testes no ambiente em que julga adequado. Para minimizar o impacto da mudança do ambiente real do usuário para um ambiente controlado é importante que este possua um espaço agradável, para que o entrevistado sinta-se a vontade e confortável ao interagir com os produtos avaliados. 


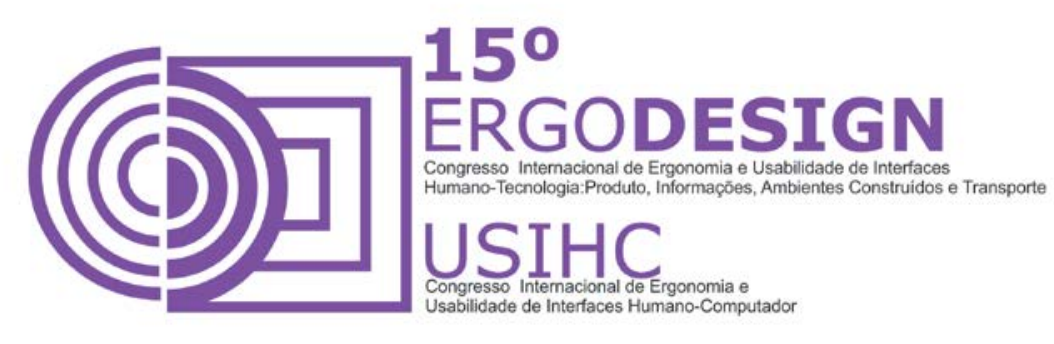

Os laboratórios de experiência do usuário podem seguir a estrutura clássica dos laboratórios de usabilidade - com sala de experimento e sala de observação separadas por uma divisória com espelho falso. Contudo é evidente a necessidade de adaptações no espaço de acordo com os objetivos dos testes de análise da experiência do usuário. Para uma análise com maior eficiência por parte dos observadores, estes laboratórios precisam de um espaço agradável e funcional, e estes pontos serão aprofundados em estudos futuros.

Muitos testes de usabilidade são realizados em salas comuns, em um ambiente frio e impessoal, porém é importante que em testes para avaliar a experiência do usuário sejam realizadas em ambientes que simulem o ambiente real. Como exemplo pode-se citar os laboratórios da Whirlpool, localizada em Joinville e da Electrolux situada em Curitiba, junto ao Instituto Lactec. A imagem 02 retrata o laboratório da Whirlpool enquanto na imagem 030 laboratório da Electrolux. Pode-se observar que os dois laboratórios simulam uma cozinha equipada e funcional, para que se possa avaliar de modo mais natural a interação dos usuários com os produtos funcionais.

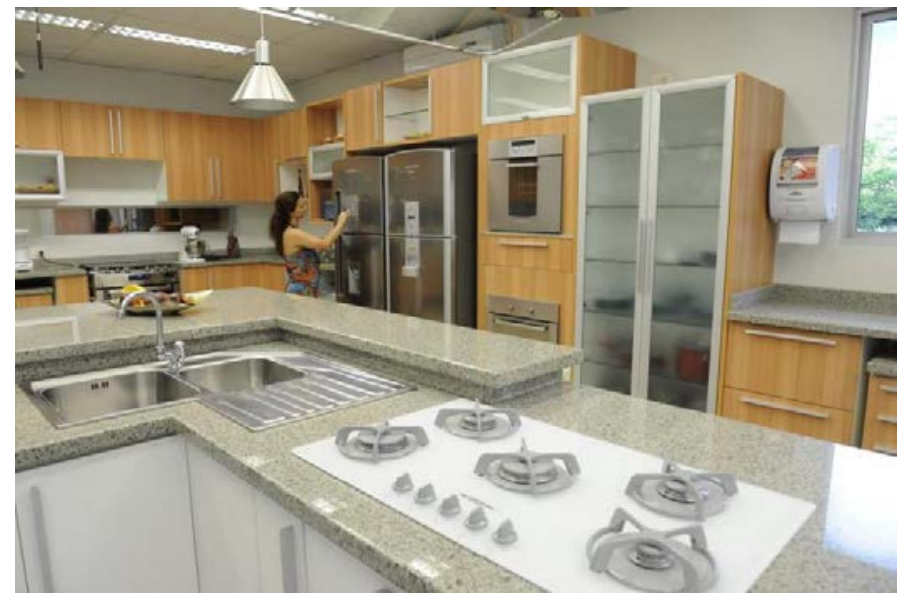

Imagem 2: laboratório de usabilidade da Whirlpool Fonte: jornal A noticia 

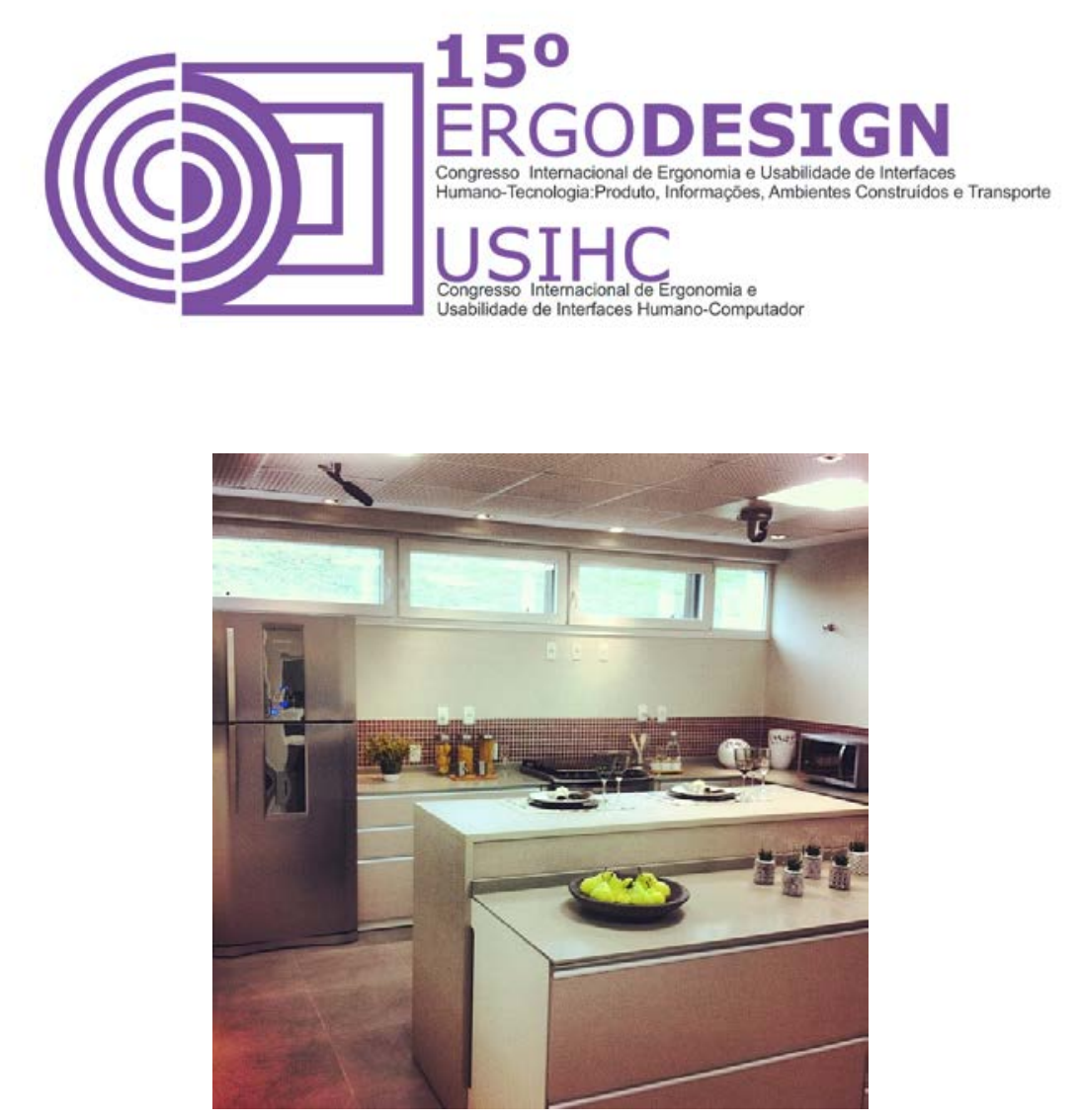

Imagem 3: laboratório de usabilidade da Electrolux Fonte: https://www.flickr.com/photos/faberludens/9063342184/in/photolist-

\section{REFERÊNCIAS BIBLIOGRÁFICAS}

ARAUJO, Fernanda Steinbruch. Avaliação da Experiência do Usuário: uma proposta de sistematização para o Processo de Desenvolvimento de Produtos. - UFSC: 2014.

CYBIS, Walter. Ergonomia e Usabilidade: conhecimentos, métodos e aplicações. São Paulo: Novatec Editora, 2007.

DESMET, Pieter. Measuring emotion; development and application of an instrument to measure emotional responses to products. In: M.A. Blythe, A.F. Monk, K.Overbeeke, \& P.C. Wright (Eds.), Funology: from usability to enjoyment (pp. 111-123), 2003.

JORDAN, P. W. An introduction to usability. London: Taylor \& Francis, 1998.

KAHNEMAN, D., KRUEGER, A. B., SCHKADE, D., SCHWARZ, N., STONE, A. A. A survey method for characterizing daily life experience: The Day Reconstruction Method (DRM). Manuscript under review, 2004.

KARAPANOS, E., ZIMMERMAN, J., FORLIZZI, J., MARTENS, J.-B.. User experience over time: an initial framework. In: CHI'09: Proceedings of the 27th International Conference on Human Factors in Computing Systems. ACM, pp. 729-738, 2009.

KHALID, M. H.; HELANDER, G. M. Customer emotional needs in product design. Concurrent Engineering Research and Applications, v. 14, n. 3, p. 197-206, 2006. ISSN 1063293X 


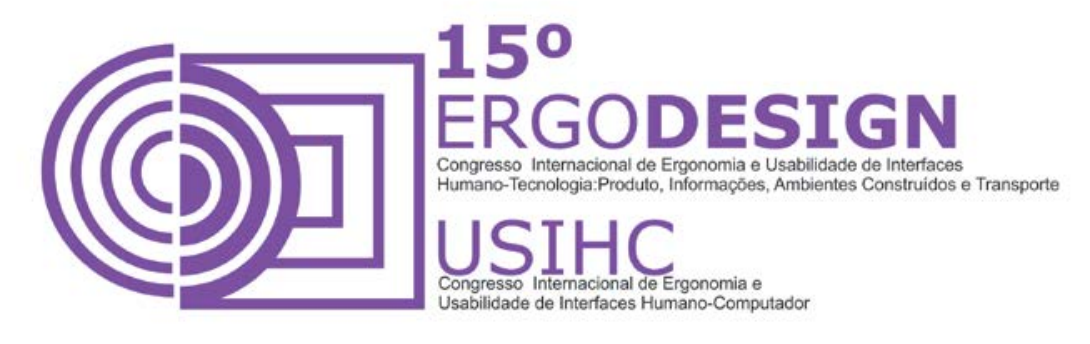

Laboratório de usabilidade Dlectrolux. Disponível em: <https://www.flickr.com/photos/faberludens/9063342184/in/photolist-> Acesso em: 10 de janeiro de 2015.

Laboratório de usabilidade Whirlpool. Jornal A Notícia. Disponível em: $<$ http://anoticia.clicrbs.com.br/sc/fotos/joinville-161-anos-confira-os-bastidores-da-maior-fabrica-degeladeiras-do-mundo-a-planta-da-whirpool-em-joinville-30971.html> Acesso em: 10 de janeiro de 2015.

NIELSEN, Jakob. Designing Web Usability: The Practice of Simplicity. Boston, USA: Academic, 2008.

NIELSEN, Jakob. Usability engineering. Boston, USA: Academic., 1993.

NIELSEN, Jakob.; MACK, R. Usability inspection methods. New York: John Willey \& Sons, 1994.

NORMAN, D. A. Interaction design is still an art form. Ergonomics is real engineering. Interactions, v. 13, n. 1, 2006.

PREECE, Jennifer; ROGERS, Yvone e SHARP, Helen. Design de Interação: Além da interação homem-computador. Tradução de Viviane Possamai. - Porto Alegre: Bookman, 2005.

RUBIN, Jeff; CHISNELL, Dana. Handbook of Usability Testing, Second Edition: How to Plan, Design, and Conduct Effective Tests. Indianapolis: Wiley Publishing, Inc., 2008.

von WILAMOWITZ-MOELLENDORFF, M., HASSENZAHL, M., PLATZ, A.. Dynamics of user experience: how the perceived quality of mobile phones changes over time. In: User Experience - Towards a Unified View - Workshop at the Fourth Nordic Conference on Human-Computer Interaction, pp. 74-78, 2006. 